\title{
The Factors that Affect Internet Addiction of Students in a Web Based Learning Environment
}

\author{
Özlem ÇAKIR BALTA* $\quad$ Mehmet Barış HORZUM***
}

\begin{abstract}
The obsessive usage of internet results in internet addiction is subjected in this study. Students who received the computer lesson on the internet have been investigated whether their addiction level changed according to gender, department, and time that they spend on the internet and their socio economic level. The research results showed that male students' level of internet addiction (LIA) was higher than female students'. It was also found that the LIA for those who spent more than 8 hours on the internet was higher than those who spent less than 8 hours in a week. It was found that there was a great significant difference among departments but students' socio-economic status didn't have a significant effect on their LIA.
\end{abstract}

Key Words: Internet Addiction, Web Based Education, Demographic Factors.

Instructor, Ankara University, Faculty of Educational Sciences, CEIT Ozlem.Cakir.Balta@education.ankara.edu.tr

*** Assist. Prof. Dr. Sakarya University, Faculty of Education CEIT, mhorzum@ @akarya.edu.tr 


\section{SUMMARY}

Purpose and Significance:

Internet addiction research focuses on the purpose of using the internet and its effects on users. When internet addiction symptoms were analyzed researchers point out that failure in courses at schools, disfunctions in social and professional areas and a feeling of fatigue in just the following day. What is important at this point is have to diagnose internet addiction. There are various techniques and approaches in the field to measure individuals' internet addiction level and to determine whether they are internetaddicted or not. In this research, Internet Addiction Scale, which was developed by Young (1998), was used.

Among the demographic factors analyzed in this research, gender, time spent on the internet, department of the individual and the socio-economic statuses of the individuals are considered to be important factors. For this reason, the main purpose of this research is to find out whether the level of internet addiction (LIA) shows any changes depending on the gender, department, the time spent on the internet and socioeconomic status of the students who took computer courses in the fall and spring of 2006-2007 academic year at Ankara University, Faculty of Educational Sciences.

Methods:

This research was designed based on single-scanning model. For the research, a group of students was chosen randomly and Internet addiction instruments were given to the students before and after taking the course. The experimental group consisted of 292 students from different departments of Ankara University, Faculty of Educational Sciences, who took computer courses in the fall and spring of 2006-2007 academic year. To obtain data, Young's Internet Addiction Scale was used and it was tested in terms of validity and reliability. Since the data collected with this scale didn't show a normal distribution, nonparametric statistics techniques were used to analyze data.

\section{Results:}

The research results showed that male students' LIA was higher than female students'. There was no significant difference between male and female students' LIAs before the course. Secondly, it was found that the LIA for those who spent more than 8 hours on the internet was higher than those who spent less than 8 hours. Thirdly, in this research, whether the department of the student affected the LIA was investigated. It was found that there was a great difference among departments. At the departmental level, it was found that students of Psychological Guidance and Counseling Department (PGC) and students of Computer Education and Instructional Technology Department (CEIT) had a high LIA, whereas students of Elementary Education and Primary Education (EEPE), Mentally Retarded Students Education (MRSE) and Pre-School Education Department (PSE) have a quite lower LIA compared to PGC and CEIT. It was found that the LIA increased significantly on a scale from the beginning to the end of the course in PGC, while in the MRSE the LIA decreases significantly from the beginning to the end of the courses. Finally, this research also shows that students' socio-economic status didn't have a significant effect on their LIA. 


\title{
Web Tabanlı Öğretim Ortamındaki Öğrencilerin İnternet Bağımlılığını Etkileyen Faktörler
}

\author{
Özlem ÇAKIR BALTA*
}

Mehmet Barış HORZUM**

\begin{abstract}
ÖZ. İnternetin aşırı kullanımının bir sonucu olan internet bağımlılığı, araştırmaya konu edilmiştir. Araştırmada, "Bilgisayara Giriş" dersini internet üzerinden alan öğrencilerin internet bağımlılık düzeylerinin; cinsiyet, öğrenim gördükleri bölüm, internete bağlı kalma saati ve sosyo ekonomik düzeylerine (SED) göre değişip değişmediği incelenmiştir. Cinsiyet yönünden erkek öğrencilerin kız öğrencilere göre; internet kullanım süresi yönünden haftada sekiz saatten fazla internete bağlı kalan öğrencilerin, haftada sekiz saatten az internete bağlı kalan öğrencilere göre; öğrenim gördükleri bölümler açısından ele alındığında öğrencilerin internet bağımlılı̆̆ düzeylerinin anlamlı derecede farklı olduğu bulunmasına rağmen, öğrencilerin SED'lerinin ise internet bağımlılığı düzeylerine etkisinin anlamlı olmadığı bulunmuştur.
\end{abstract}

Anahtar Sözcükler: İnternet Bağımlılığı, Web Tabanlı Eğitim, Demografik Faktörler.

\section{GíRiş}

Gelişen dünyada internetin temel ortaya çıkış amacı iletişimi artırarak, bilgi paylaşımını kolaylaştırmak ve araştırmacılara yeni olanaklar sunmaktır. İnternetin günlük yaşamdaki öneminin artmasıyla birlikte, değişik alanlardan daha fazla kişi her gün çeşitli nedenlerle internete bağlanmakta ve interneti kullanmaktadır. Bu alanlardan biri de eğitim-öğretim kurumlarındaki kullanımıdır. İnternetin akademik kullanımı öncelikli olarak öğrenme ve araştırma amaçlı iken zamanla internet öğrencilerin hayatlarının önemli bir parçası durumuna gelmiştir. İnternetin

* Öğr. Gör., Ankara Üniversitesi, Eğitim Bilimleri Fakültesi, BÖTE Bölümü,

Ozlem.Cakir.Balta@education.ankara.edu.tr

*** Yrd. Doç. Dr. Sakarya Üniversitesi, Eğitim Fakültesi, BÖTE Bölümü,

mhorzum@sakarya.edu.tr 
popülerliğinin artması, insanları aşırı kullanıma doğru yöneltmiş̦tir (Chou, Condron ve Belland, 2005). Araştırmalar incelendiğinde, insanların davranışlarında olumsuz etkilere neden olan aşırı internet kullanımı, internet bağımlılığı olarak adlandırılmakta ve çağdaş bilgi topluluğunda oldukça yaygınlaştı̆̆ vurgulanmaktadır (Young, 1998; Kandell, 1998; Tsai Lin, 2001; Griffiths, 2000, 2005).

İnternet bağımlılı̆̆ ilk olarak Young (1997) tarafindan ortaya atılmış bir kavramdır. Bağımlılık ile ilgili alan yazın incelendiğinde 2000'li yıllara kadar internet bağımlılığının, bağımlılık olup olmadığı tartışılmakta iken artık günümüzde böyle bir bağımlılığın varlığı kabul edilmekte hatta tedavisi üzerinde durulmaktadır. Öyle ki Ege Üniversitesi'nde "internet bağımlılığı" adıyla bir ders açılmış (İnternet resmen hastalık, 2006) ve Balıklı Rum Hastanesi artık "internet bağımlılarını" tedavi etmeye başlamıştır (İnternet hastasıyım, 2006).

İnternet bağımlılığı ile ilgili araştırmalar incelendiğinde; genel olarak internet kullanım şekli ve internetin neden olduğu sonuçların ele alındığı ve incelendiğ görülmektedir. Cengizhan (2003) ve Young'a (2005) göre, internet bağımlılığının belirtileri;

* Yalnızca bir kaç dakika harcamaya niyetli olunmasına rağmen saatler harcama;

* Arkadaşlarına yalan söyleme;

* Ekranın başında her oturuşta saatlerce kaldığı için fiziksel sorunlara maruz kalma;

* Sürekli olarak bir sonraki bağlanma zamanını bekleme;

* Aradığı bilgiyi bulmada hep bir adımcık kaldığını düşünme;

* İnsanlar ile internet üzerinden konuşmayı, insanlarla yüz yüze konuşmaktan daha rahat bulma;

* E-postada yeni bir şeyler var mı diye bakmak için sürekli istek duyma;

* İnternete girmek ya da internette kalmak için yemek öğünlerini, derslerini veya randevularını görmezden gelme;

* İnternetin başında bu kadar fazla zaman geçirdiği için suçluluk duyma ve hoşlanma arasında gidip gelme;

* Herkese mail adresi, sohbet odası adları ve ICQ numarası verme veya dağıtmaya çalışma;

* İnternet dışı uğraşlara ilginin kaybolması ve iş verimliliğinin düşmesi;

* İnternette çok geç saatlere bağlı kalmak yüzünden sürekli uykusuz kalma ve yorgunluk;

* Bilgisayar kullanımı nedeniyle eşler arasında anlaşmazlık ve sorun çıkması olarak ifade edilmiştir. 
Cengizhan (2003) ve Young'ın (2005) ortaya koyduğu bu belirtiler incelendiğinde internet bağımlılı̆̆ının; belirgin derecede artan bilgisayar ve internet kullanımı ile ders başarısızlığına, sosyal ve mesleki yönde aksamalara ve başarısızlıklara, hemen her gece önlenemeyen internet kullanımı isteği ve ertesi güne sarkan yorgunluk hissine neden olduğu görülmektedir. Bu noktada internet bağımlılı̆̆ının nasıl tespit edileceği önem kazanmaktadır.

Alan yazın incelendiğinde, kişilerin internet bağımlılı̆̆ düzeylerinin ve internet bağımlısı olup olmadıklarının ölçülmesi ile ilgili farklı ölçüm şekillerinin ve yaklaşımların bulunduğu görülmektedir. Örneğin; Young $(1998,1999)$ internet bağımlılığını bir testle, Cengizhan (2003) ise, bağımlılı̆̆ ifade eden maddelerden oluşan ölçek aracilığı ile ölçmeyi tercih etmiştir. Beard (2005) ölçek kullanmak ya da haftalık internet kullanım süresini dikkate almak yerine, bağımlılık ölçeklerinde yer alan soruları açık uçlu sorulara çevirerek oluşturduğu klinik görüşme formunun kullanılmasını önermektedir. Thompson (1996), kişinin kendisini internet bağımlısı hissedip hissetmediğini temel almaktadır. Brenner (1996) ise haftada 40 saatten fazla internet kullananları bağımlı olarak kabul etmektedir (Akt. Cengizhan, 2003). İncelenen bu araştırmalar arasında en çok Young'ın internet bağımlılığı testinin kullanıldığı görülmektedir. Bu yönüyle araştırmada Young'ın testi kullanılmıştır.

Ngai (2007), Young'ın internet bağımlılı̆̆ı testini Hong Kong’ta 10 ile 15 yaşları arasındaki 5-9. sınıflarda okuyan öğrencilerde kullanarak geçerlilik ve güvenirlilik çalışmaları yürütmüş̧ür. Katılımcılar Hong Kong okulundan random olarak seçilmiştir. Katılımcıların cevaplarından 988 tanesi kullanılabilir bulunmuş ve bu veriler geçerlilik ve güvenirlilik için kullanılmıştır. Faktör analizi çalışmalarında 20 maddelik test 4 faktörlü bir yapıya sahip çıkmıştır. Yine çalışmada güvenirlilik için faktörlerin iç tutarlık katsayıları 0.63-0.82 arasında bulunmuştur. Ceyhan, Ceyhan ve Gürcan (2007) araştırmalarında üniversite öğrencilerinde problemli internet kullanımını belirlemeye yönelik bir ölçme aracı geliştirmeyi amaçlamışlardır. 1658 üniversite öğrencisinden elde edilen veriler, ölçeğin üç faktörden oluştuğunu ortaya koymuştur. Toplam 33 maddeden oluşan bu üç faktör birlikte toplam varyansın \% 48,96'sını açıklamıştır. Ölçeğin, haftalık internet kullanım süresi ve kendisini internet bağımlısı olarak algılama durumuna göre bireylerin problemli internet kullanım davranışını ayırt edebildiği bulunmuştur. Ölçekteki madde toplam puan güvenirlilik katsayıları 0.31 ile 0.70 arasında bulunmuştur. Testin tekrarı güvenirlilik katsayısı 0.81 ve iki parçası arasındaki korelasyon 0.83 olarak bulunmuştur.

Araştırmalardan, en çok Young'ın internet bağımlılığı testinin kullanıldığına anlaşılmakta birlikte, son zamanlarda yapılan çalışmalarda ise bu testin geçerlilik ve güvenilirliğine odaklanıldığı görülmektedir. Ayrıca internet bağımlılığı konusunun 90'lı yılların ortalarından itibaren araştırılmaya başlanan yeni bir alan olduğu anlaşılmaktadır. Yukarıdaki araştırmalarda internet bağımlılığını ölçmenin yanında, daha çok problematik internet kullanımında, yüksek riskli gruplar ve bağımlı davranışların kişilikle bağlantısının incelendiği görülmektedir (Chak Leung, 2004). 
Young (1998) çalışmasında, daha sonra yapılacak araştırmaların bağımlılıkla ilgili çeşitli demografik faktörlere odaklanmasını önermektedir. Chou (2005) internet bağımlılığı ile ilgili inceledikleri araştırmaları; haftalık internet kullanım süresi, cinsiyet, psikolojik durum ve bilgisayar tutumu gibi değişkenlerle ilişkili olarak sınıflamaktadırlar. Bu yönüyle, araștırmalar incelendiğinde cinsiyet, sosyo ekonomik düzey (SED) ve internet kullanım süreleri gibi değişkenler internet bağımlılığını etkileyen etmenler olarak karşımıza çıkmaktadır ki Chak ve Leung (2004) de güncel araştırmalarda, internet bağımlılığı ile ilgili değişkenlere odaklanılmasını önermektedirler. Bu yönüyle alan yazındaki araştırmalarda ele alınan değişkenleri incelemekte fayda görülmektedir.

İnternet bağımlılı̆̆ı ile ilgili araştırmalarda cinsiyet değişkeni açısından farklı sonuçlara rastlanmaktadır: Morahan-Martin ve Schumacker (2000) ile Chou (2005)'nin araştırmalarında, erkeklerin kızlara göre daha çok internet bağımlısı olduğu; Young'ın (1998) araştırmasında kızların erkeklere göre daha çok internet bağımlısı olduğu; Brenner (1997), Soule, Shall ve Kleen (2003), Lee ve diğerleri (2007) ile Ferraro ve diğerlerinin (2007) araştırmalarında ise kızlarla erkekler arasında internet bağımlılığı açısından fark olmadığı ortaya çıkmıştır. Sonuç olarak araştırmalarda cinsiyet yönünden tutarlı bulgulara rastlanamadığından bu konunun araştırılması önem arz etmektedir.

Chou ve diğerleri (2005) inceledikleri araştırmalarda, öğrencilerin internet bağımlılık puanları ile haftalık internet kullanım oranlarının ilişkili olduğunu bulmuşlardır. Ngai'de (2007) araştırmasında toplam internet bağımlılığı puanı ile ortalama internet kullanım süreleri arasında pozitif anlamlı ilișki olduğunu ortaya koymuştur. Bununla birlikte Tsai ve Lin (2003) bağımlı öğrencilerin internet kullanım süresi yönetimi konusunda zorlandıklarını ve internet başında çok vakit geçirdikleri sonucuna ulaşmışlardır. Geçirilen bu sürenin aşırısının internet bağımlılığına neden olduğunu vurgulamışlardır. Bu yönüyle araştırmalarda internet bağımlılığının en önemli yordayıcılarından birisi olarak internet kullanım süresi bulunmuştur. Bu sonuç Young (1998) ile Chou ve Hsiao'nin (2000) bulgularıyla da tutarlıdır. Ancak, bu araştırmalarda haftalık internet kullanım süresi açısından farklı bulgular yer almaktadir: Brenner (1996, Akt. Cengizhan, 2003), haftada 40 saatten fazla internet kullananları; Scherer (1997, Akt. Cengizhan, 2003), haftada ortalama 11 saat ve fazlasını; Young (1998), haftada yaklaşık 39 saat internet kullanım süresine sahip olanlar1, Morahan-Martin ve Schumacker (2000) ile Nalwa ve Anand (2003), haftada 8-14 saat arası internet kullanım süresine sahip olanları; Chou ve Hsiao (2000), 20-25 saat arasında haftalık internet kullanım süresine sahip olanları; Lee ve diğerleri (2007), haftada 21-40 saat internet kullanım süresine sahip olanları internet bağımlısı olarak kabul etmektedirler. Bu bağlamda; araştırmalarda internet bağımlısı kişilerin, internet kullanım süreleri açısından farklı bulguların olması, bu konunun tekrar incelenmesi bakımından önemlidir.

Young (1998) işi tamamen internet üzerinde olan kişilerin daha fazla internette kaldıklarını ve bu kişilerin bağımlı olma eğilimlerinin arttığını belirtmektedir. $\mathrm{Bu}$ nedenle; günümüzde uygulamaları gittikçe artan, web tabanlı öğretim uygulamalarına katılan öğrencilerin, internet bağımlılığı düzeylerinin yüksek olması beklenmektedir. 
İnternet bağımlılığı ile SED arasındaki farkı araştıran sınırlı sayıda araștırmaya ulaşılmıştır. Yoo ve diğerleri (2004) araştırmalarında bağımlılık ile SED arasında anlamlı ilişki bulamamışlardır. SED ile ilgili ulaşılan araştırma sayısının az olması bu değişkenin araştırmada konu edilmesi açısından önemli görülmektedir.

Kandell (1998), üniversite öğrencilerinin diğer öğrencilerden daha fazla internet bağımlısı olduğunu belirtmektedir. Bunun nedeni olarak; üniversite öğrencilerinin evlerinden uzak yurtlarda yaşamakta olduğu, ailelerinin yönlendirmeleri olmadan boş vakitlerini yanlış değerlendirebilmeleri, bu dönemdeki öğrencilerin kişilerarası ilişkilere yönelmeleri ve eğitim sisteminin öğrencileri internet kullanımına yönlendirmesi gösterilmektedir. $\mathrm{Bu}$ nedenle araştırma üniversite öğrencileri üzerinde yapılmıştır.

İnternet bağımlılığı ile ilgili araştırmalar özellikle $A B D$ ve Batı Avrupa ülkelerinde yapılmış olmakla birlikte, son zamanlarda alan yazında Uzakdoğu ülkelerinden de yayınlarla karşılaşılmaktadır (Öztürk ve diğerleri, 2007). Türkiye dışında internet kullanımı ve bağımlılığı ile ilgili birçok yayın olmasına karşın Türkiye'de bu alanda yapılmış çalışma sayısı oldukça azdır (Köroğlu ve diğerleri, 2006). Türkiye'de genç nüfusun fazlalığı, internetin yaygınlaşma hızının yüksekliği ve işsizlik gibi sosyo ekonomik nedenlerden dolayı, internet bağımlılığının özellikle de okullarda daha fazla olacağı düşünülmektedir (Öztürk ve diğerleri, 2007).

Dolayısıyla, internet bağımlılığı ile ilgili çalışmalarda konu edilen demografik özelliklerden, farklı bulgulara sahip değişkenler olan; cinsiyet, haftalık internet kullanım süresi gibi değişkenlerle öğrenim gördükleri bölüm, SED araştırılmaya değer görülmektedir. Bu bilgiler temel alınarak planlanan bu araştırmanın temel amacı: Ankara Üniversitesi Eğitim Bilimleri Fakültesinde 2006-2007 öğretim yılı güz ve bahar yarıyılında Bilgisayara Giriş (Bilgisayar I, Eğitimde Bilişim Teknolojileri I ve Bilgisayar) dersini internet üzerinden alan öğrencilerin, internet bağımlılık düzeyinin; cinsiyet, öğrenim gördükleri bölüm, haftalık internet kullanım süresi ve SED’lerine göre değişiklik gösterip göstermediğini ortaya koymaktır.

\section{YÖNTEM}

\section{Araştırmanın Modeli}

Araştırma, tarama modellerinden, tekil tarama modeline uygun olarak planlanmış ve gerçekleştirilmiş̧tir. Tekil tarama modelinde; ilgilenilen olay, grup gibi birim ve duruma ait değişkenler, ayrı ayrı betimlenmeye çalışılır. Bu betimlenmede geçmiş ya da şimdiki zamanla sınırlı olabileceği gibi, zamanın bir fonksiyonu olarak gelişimsel de olabilir. Yani bu modelde, anlık durum saptamalarının yanında zamansal değişimler ve gelişimler de belirlenebilmektedir (Karasar, 2004). Bu araştırmada da yansız seçilmiş bir grubun web tabanlı öğrenme etkinliklerinde ders öncesi ve sonrası internet bağımlılı̆̆ düzeylerinin, bu gruba ait değişkenlere göre farklılık gösterip göstermediği ortaya konulmak istendiği için tekil tarama modeli seçilmiştir. Tekil tarama modelinde ders öncesi ve sonrası değişim inceleneceği için zamansal taramalar temel alınarak 
izleme yaklaşımı belirlenmiştir. Araştırmada ders öncesi ve sonrası ölçümleri arasında bir dönemlik süre geçmiştir.

\section{Çalışma Grubu}

Araştırmanın çalışma grubunu; 2006-2007 öğretim yılı güz ve bahar yarıyılında Ankara Üniversitesi Eğitim Bilimleri Fakültesi’nin altı farklı bölümünde, Bilgisayara Giriş (Bilgisayar I, Eğitimde Bilişim Teknolojileri I ve Bilgisayar) dersini alan toplam 292 öğrenci oluşturmuştur (2006-2007 öğretim yllında Bilgisayara Giriş dersi içerik olarak aynı olmakla birlikte, bölümlere farklı isimlerde ve farklı dönemlerde verilmiştir). $\mathrm{Bu}$ öğrencilerin seçiminde dersi alan tüm öğrenciler çalışma grubuna seçilmiş ancak derse katılmayan ve veri toplanamayan öğrenciler araştırmadan çıkarılmıştır.

\section{Uygulama}

Araştırmada öğrencilere, Avrupa Bilgisayar Yetkinlik Sertifikası (ECDL) eğitimi kapsamında yer alan yedi modülden oluşan içeriğe, web tabanlı öğrenme etkinlikleriyle dönem boyunca erişim imkanı sağlanmıştır. Öncelikle öğrencilere ECDL sistemi anlatılmış ve öğrenme etkinliklerine erişim sağlayacak şifreleri verilmiştir. Öğrenciler kendi şifreleri ile ECDL sistemine giriş yapıp, sistem üzerinde anlatılan dersleri dinlemiş ve sistemde belirtilen uygulamaları yapmışlardır. Öğrencilerin derse devamı için haftalık olarak şifre değiştirilmiştir. Öğrencilere verilen bu şifre aracıllğıyla, istedikleri zaman, herhangi bir internet bağlantısının olduğu yerden dersin içeriğine erişim olanağı sağlanmıştır. Ders içeriği ve uygulamalar internet üzerinden araştırmacilar tarafindan takip edilmiş, yaşanan sorunlar öğretmen ile ders saatinde yüz yüze görüşülmüş ve sorunlara çözüm üretilmiştir.

\section{Veri Toplama Aracı}

$\mathrm{Bu}$ araştırmada, kullanılan veri toplama aracı olan "İnternet Bağımlılığı Testi" Young tarafindan 1998 yilında geliştirilmiştir. Testin orijinalinde geçerlilik ve güvenirlilik çalışması olmadığı için, öncelikle geçerlilik ve güvenirlilik çalışmaları yapılmıştır. Bu çalışmalar uygulamadan bir dönem önce araştırma grubuna benzeyen bir grupla gerçekleştirilmiş̧ir. Geçerlilik ve güvenirlilik çalışmalarından önce testin maddeleri Türkçe'ye çevrilerek beş alan uzmanından görüs alınmış, düzeltmeler yapılmış ve çeviri işlemleri tamamlanmıştır. Daha sonra geçerlilik ve güvenirlilik için test, internet üzerinden ders almış olan 250 öğrenciye uygulanmıştır. Bu öğrencilerden elde edilen veriler, yapı geçerliği için açımlayıcı faktör analizi, güvenirliği ise Cronbach $\alpha$ iç tutarlılık katsayısı ile test edilmiştir. 20 maddelik testten güvenirliği düşürdüğü için bir madde atılarak 19 maddeden oluşan ölçek elde edilmiş̧tir. Bu ölçek üç boyuttan oluşmakta ve bu boyutlardaki faktör yük değeri .811-.398 arasında değişmektedir. Ölçekle toplam açıklanan varyans \% 52.83 ve Cronbach $\alpha$ değeri .895 'tir. Ölçeğin birinci boyutu olan "çevrim-içi olmayı günlük hayata tercih etme" toplam sekiz maddeden oluşmaktadır. Bu maddelerden bir tanesi "Hangi skklkkla interneti samimi bir arkadaşınıza tercih ediyorsunuz?"dur. Bu maddelerin faktör yük değeri .811-.398 arasında değişmekte ve açıkladığı toplam varyans \% 36.34'tür. Bu boyut için hesaplanan Cronbach $\alpha$ değeri .80 'dir. İkinci boyut olan "çevrim-içi olma süresini 
artırmak isteme" toplam yedi maddeden oluşmaktadır. Bu maddelerden bir tanesi "Hangi sıklıkla ailenizle ilgili işleri ihmal ederek çevrim-içi ortamda daha fazla zaman harcıyorsunuz?'dur. Bu maddelerin faktör yük değeri .696-.476 arasında değişmekte ve açıkladığı toplam varyans \% 9.28'dir. Bu boyut için hesaplanan Cronbach $\alpha$ değeri .79'dur.

Üçüncü boyut olan "çevrim-içi olmaktan kaynaklanan sorunlar" toplam dört maddeden oluşmaktadır. Bu maddelerden bir tanesi "Hangi sıklıkla hayatınızdaki diğer kişiler çevrim-içi olarak harcadığınız zaman süresi hakkında şikayet etmektedir?’dir. $\mathrm{Bu}$ maddelerin faktör yük değeri .795-.533 arasında değişmekte ve açıkladığı toplam varyans \% 7.21'dir. Bu boyut için hesaplanan Cronbach $\alpha$ değeri .78'dir.

Ölçek aynı zamanda tek faktörlüdür. Bunun nedeni maddelerin döndürülme öncesindeki birinci faktör yük değerlerinin yüksek olması ve tek başına açıkladığı varyansın yüksek olması ölçeğin genelde bir faktöre de sahip olduğunu göstermektedir. $\mathrm{Bu}$ nedenle araştırmada ölçeğin tek faktörlü kullanımı tercih edilmiştir.

\section{Verilerin Toplanması ve Analizi}

Araştırmanın verileri 2006-2007 öğretim yılı güz ve bahar yarıyılının bilgisayar dersi başlangıcında ve sonunda yapılan ölçümler sonunda elde edilmiştir. Bu verilerin tek örneklem Kolmogorov-Smirnov Testine göre normal dağılım göstermemesi nedeniyle non-parametrik istatistikler uygulanmıştır. Burada cinsiyet ve bağlı kalma saati için Mann Whitney U Testi ve ögrenim gördükleri bölüm ve SED için Kruskal Wallis H Testi yapılmıştır. Öğrencilerin öğrenim gördükleri bölümler arasında anlamlı farklılık bulunduğunda ise hangi bölümde fark olduğuna Mann Whitney U Testi ile bakılmıştır. Bunun yanında dersin işlenmesinden önceki durum ile sonraki durumlarının değişimine Wilcoxon İşaretli Sıralar Testi ile bakılmıştır.

\section{BULGULAR}

Araştırmada bulgular; cinsiyet, haftalık interneti kullanma süresi, öğrenim gördükleri bölüm ve SED sırasıyla sunulmuştur. Öncelikle cinsiyete ilişkin olarak Mann Whitney U Testi yapılmıştır. Test sonucunda elde edilen veriler aşağıdaki tabloda yer almaktadır.

Tablo 1. Öğrencilerin cinsiyetlerine göre ders öncesi ve sonrasındaki internet bă̆ımlılı̆̆ı düzeylerinin Mann Whitney U Testi sonuçları

\begin{tabular}{ccccccc}
\hline & CINSIYET & $N$ & SO & $\begin{array}{c}\text { Kareler } \\
\text { Ort. }\end{array}$ & $U$ & $p$ \\
\hline Ders & Kiz & 168 & 110.41 & 18549.50 \\
Öncesi & Erkek & 67 & 137.02 & 9180.50 & 4353.50 & $.007 * *$ \\
\hline Ders & Kiz & 168 & 109.68 & 18426.50 & 4230.50 & $.003 * *$ \\
Sonras1 & Erkek & 67 & 138.86 & 9303.50 & \\
\hline
\end{tabular}

Araştırmaya katılan öğrencilerin internet bağımlılık düzeyleri cinsiyetlerine göre karşılaştırıldığında ders öncesinde $(U=4353.50, p<.05)$ ve sonrasında $(U=4230.50$, $\mathrm{p}<.05)$ istatistiksel olarak anlamlı farklılık olduğu görülmektedir. Sira ortalamaları (SO) dikkate alındığında bu farkın, ders öncesinde de sonrasında da erkek öğrencilerin internet bağımlılı̆̆ı düzeylerinin $\left(\mathrm{SO}_{(\ddot{\mathrm{o}})}=137.02, \mathrm{SO}_{(\text {son })}=138.86\right) \mathrm{kız}$ öğrencilerin 
internet bağımlılı̆̆ düzeyinden $\left(\mathrm{SO}_{(\ddot{\mathrm{ön}})}=110.41, \mathrm{SO}_{(\mathrm{son})}=109.68\right)$ daha fazla olmasından kaynaklandığı görülmektedir. Bu bulgu araştırmaya katılan erkek öğrencilerin internet bağımlılığı düzeyinin ders öncesinde de sonrasında da yüksek olduğunu ortaya koymaktadır.

Araştırmada erkek ve kız öğrencilerin ders öncesinden sonrasına internet bağımlılığı düzeylerinin değişip değişmediğine Wilcoxon İşaretli Sıralar Testi ile bakılmıştır. Wilcoxon İşaretli Sıralar Testinden elde edilen sonuçlar aşağıdaki tabloda yer almaktadır.

Tablo 2. Klz ve erkek ögrencilerin ders öncesi ve sonrasındaki internet bă̆ımlılı̆̆ düzeylerinin değişip değişmediğine yönelik Wilcoxon Işaretli Sıralar Testi sonuçları

\begin{tabular}{lllllll}
\hline Ders Öncesi-Sonrası & $N$ & SO & Sira Top. & $z$ & $p$ \\
\hline K1z & Negatif Sıra & 82 & 76.38 & 6263.50 & & \\
& Pozitif Sıra & 69 & 75.54 & 5212.50 & -.978 & .328 \\
& Eşit & 17 & & & & \\
\hline Erkek & Negatif Sıra & 34 & 29.56 & 1005.00 & & \\
& Pozitif Sıra & 28 & 33.86 & 948.00 & -.200 & .841 \\
& Eşit & 5 & & & & \\
\hline
\end{tabular}

Tablo 2 incelendiğinde Wilcoxon İşaretli Sıralar Testi sonucunda öğrencilerin cinsiyetlerine göre internet bağımlılığı düzeylerinin, ders öncesinden sonrasına istatistiksel olarak $\left(\mathrm{z}_{(\mathrm{klz})}=-.978\right.$ ve $\left.\mathrm{z}_{(\mathrm{erkek})}=-.200, \mathrm{p} .>05\right)$ anlamlı derecede değişim göstermediği bulunmuştur.

Araştırmada ikinci olarak haftalık interneti kullanma süresine ilişkin Mann Whitney $U$ testi yapılmıştır (Tablo 3). Araştırmaya katılan öğrencilerin internet bağımlılık düzeyleri haftalık interneti kullanma sürelerine göre karşılaştırıldığında, ders öncesinde $(U=3395.00, p<.05)$ ve sonrasinda $(U=3551.00, p<.05)$ istatistiksel olarak anlamlı farklılık olduğu görülmektedir. Tablo 3'te yer alan SO'ları incelendiğinde bu farkın ders öncesinde de, sonrasında da haftada sekiz saatten fazla internete bağlanan öğrencilerin internet bağımlılığı düzeylerinin $\left(\mathrm{SO}_{(\text {ön }}=149.34, \mathrm{SO}_{(\text {son })}=146.79\right)$ sekiz saatten az internete bağlanan öğrencilerin internet bağımlılığı düzeyinden $\left(\mathrm{SO}_{(\ddot{\mathrm{on}})}=\right.$ 107.01, $\left.\mathrm{SO}_{(\mathrm{son})}=107.91\right)$ daha fazla olmasından kaynaklandığı görülmektedir. Bu bulgu; internet bağımlılık düzeyinin, haftalık interneti kullanma süresine göre değiștiğini göstermektedir.

Tablo 3. Öğrencilerin haftalık interneti kullanma sürelerine göre ders öncesi ve sonrasındaki internet bağımlılığ

\begin{tabular}{lcccccc}
\hline $\begin{array}{l}\text { Haftalık İnternet Kullanım } \\
\text { Süresi }\end{array}$ & N & SO & Kareler Ort. & U & p \\
\hline Ders Öncesi & 8 Saate Kadar & 174 & 107.01 & 18620.00 & & \\
& 8 Saatten Fazla & 61 & 149.34 & 9110.00 & 3395.00 & $.000 * *$ \\
\hline Ders Sonras1 & 8 Saate Kadar & 174 & 107.91 & 18776.00 & & \\
& 8 Saatten Fazla & 61 & 146.79 & 8954.00 & 3551.00 & $.000 * *$ \\
\hline
\end{tabular}


Haftalık interneti kullanma süresi yönünden haftada sekiz saatten fazla bağlı kalan ve haftada sekiz saatten az bağlı kalan öğrencilerin ders öncesinden sonrasına, internet bağımlılığı düzeylerinin değişip değişmediğine Wilcoxon İşaretli Sıralar Testi ile bakılmıştır. Wilcoxon İşaretli Sıralar Testinden elde edilen sonuçlar aşağıdaki tabloda yer almaktadır.

Tablo 4. Öğrencilerin haftalık interneti kullanma sürelerine göre ders öncesi ve sonrasındaki internet bă̆ımlılı̆̆ düzeylerinin dĕ̆işip değişmediğine yönelik Wilcoxon İsaretli Stralar Testi sonuçları

\begin{tabular}{lllllll}
\hline Ders Öncesi - Ders Sonrast & $N$ & SO & Sira Top. & $z$ & $p$ \\
\hline 8 Saate Kadar & Negatif Sıra & 82 & 77.60 & 6363.00 & & \\
& Pozitif Sıra & 72 & 77.39 & 55.72 & -.715 & .475 \\
& Eşit & 19 & & & & \\
\hline 8 Saatten Fazla & Negatif Sıra & 34 & 28.47 & 968.00 & & \\
& Pozitif Sıra & 25 & 32.08 & 802.00 & -.627 & .531 \\
& Eşit & 3 & & & & \\
\hline
\end{tabular}

Tablo 4 incelendiğinde Wilcoxon İşaretli Sıralar Testi sonucunda; öğrencilerin haftalık interneti kullanma süresine göre internet bağımlılığı düzeylerinin, ders öncesinden sonrasına istatistiksel olarak $\left(\mathrm{z}_{(8 \text { saatten fazla })}=-.627\right.$ ve $\left.\mathrm{z}_{(8 \text { saatten az })}=-.715, \mathrm{p}>.05\right)$ anlamlı derecede değişim göstermediği bulunmuştur. Araştırmada üçüncü olarak öğrencilerin öğrenim gördükleri bölümlere göre internet bağımlılık düzeylerinin değişip değişmediğine ilişkin Kruskal Wallis $\mathrm{H}$ Testi yapılmıştır. Bu test sonucunda elde edilen bulgular aşağıdaki tabloda yer almaktadır.

Tablo 5. Öğrencilerin ögrrenim gördükleri bölümleri yönünden ders öncesi ve sonrasındaki internet bağımlılı̆̆ düzeylerinin Kruskal Wallis H Testi sonuçları

\begin{tabular}{|c|c|c|c|c|c|c|}
\hline & BÖLÜM & $\mathrm{N}$ & SO & $\chi^{2}$ & df & $\mathrm{p}$ \\
\hline \multirow{6}{*}{ 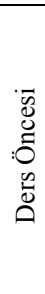 } & SÖ & 88 & 121.44 & \multirow{6}{*}{4.44} & \multirow{6}{*}{5} & \multirow{6}{*}{.488} \\
\hline & PDR & 53 & 114.25 & & & \\
\hline & ZEÖ & 26 & 125.35 & & & \\
\hline & OÖÖ & 31 & 96.97 & & & \\
\hline & SBÖ & 12 & 125.00 & & & \\
\hline & BÖTE & 25 & 128.94 & & & \\
\hline \multirow{6}{*}{ 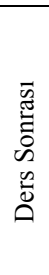 } & SÖ & 88 & 113.14 & \multirow{6}{*}{13.85} & \multirow{6}{*}{5} & \multirow{6}{*}{$.017 * *$} \\
\hline & PDR & 53 & 136.28 & & & \\
\hline & ZEÖ & 26 & 102.60 & & & \\
\hline & OÖÖ & 31 & 91.89 & & & \\
\hline & SBÖ & 12 & 119.92 & & & \\
\hline & BÖTE & 25 & 143.82 & & & \\
\hline
\end{tabular}


Araştırmaya katılan öğrencilerin internet bağımlılık düzeyleri, öğrenim gördükleri bölümlere göre karşılaştırıldığında; ders öncesinde istatistiksel olarak anlamlı bir farklılık olmamasına rağmen $\left(\chi^{2}=4.44, \mathrm{p}>.05\right)$, ders sonrasında istatistiksel olarak anlamlı farklılık olduğu $\left(\chi^{2}=13.85, \mathrm{p}<.05\right)$ bulunmuştur. Ders sonrasındaki bu farklılığın hangi bölümler arasında olduğunu görmek amaciyla bölümler tek tek birbirleri arasında Mann Whitney U Testi ile karşılaştırılmıştır. Mann Whitney U Testlerinden elde edilen sonuçlar aşağıdaki tablolarda sunulmuştur.

Tablo 6. Öğrencilerin öğrenim gördükleri bölümlerden SÖ ile diğer bölümler arasında ders sonrasındaki internet bağımlılı̆̆ı düzeylerinin değişimi Mann Whitney U Testi tablosu

\begin{tabular}{cccccc}
\hline BÖLÜM & N & SO & Kareler Ort. & U & p. \\
\hline SÖ & 88 & 65.66 & 5778.00 & \multirow{2}{*}{1862.00} & $.045 * *$ \\
PDR & 53 & 79.87 & 4233.00 & & .501 \\
\hline SÖ & 88 & 58.63 & 5159.50 & 1044.50 & \\
ZEÖ & 26 & 53.67 & 1395.50 & & .120 \\
SÖ & 88 & 62.91 & 5536.00 & 1108.00 & \\
OÖÖ & 31 & 51.74 & 1604.00 & & .726 \\
SÖ & 88 & 50.13 & 4411.00 & \multirow{2}{*}{495.00} & \\
SBÖ & 12 & 53.25 & 639.00 & & $.048 * *$ \\
SÖ & 88 & 53.82 & 4736.00 & \multirow{2}{*}{$* 00.00$} & \\
BÖTE & 25 & 68.20 & 1705.00 & & \\
\hline
\end{tabular}

Mann Whitney U Testi sonuçları incelendiğinde Sınıf Öğretmenliği Bölümü (SÖ) ile Psikolojik Danışma ve Rehberlik Bölümü (PDR) öğrencileri (U= 1862.00) ve Bilgisayar ve Öğretim Teknolojileri Eğitimi Öğretmenliği Bölümü (BÖTE) öğrencileri $(\mathrm{U}=800.00)$ arasında internet bağımlılığı düzeyleri yönünden istatistiksel olarak anlamlı bir farklılık olduğu $(\mathrm{p}<.05)$ bulunmuştur. Bunun yanında SÖ ile diğer bölümler arasında ise internet bağımlılığı düzeyleri yönünden istatistiksel olarak anlamlı bir farklılık olmadığı $(\mathrm{p}>.05)$ ortaya çıkmıştır. Aralarında anlamlı farklılık bulunan bölümlerin SO'ları dikkate alındığında PDR öğrencilerinin internet bağımlılığı düzeyleri $(\mathrm{SO}=79.87) \mathrm{SÖ}(\mathrm{SO}=65.66)$ öğrencilerine göre anlamlı derecede yüksek olduğu görülmektedir. Aynı zamanda BÖTE öğrencilerinin internet bağımlılığı düzeylerinin de $(\mathrm{SO}=68.20) \mathrm{SÖ}(\mathrm{SO}=53.82)$ öğrencilerine göre anlamlı derecede yüksek olduğu bulunmuştur. 
Tablo 7. Öğrencilerin öğrenim gördükleri bölümlerden PDR ile dĭger bölümler arasında ders sonrasındaki internet bağımlılığ dü̈eylerinin değișimi Mann Whitney U Testi tablosu

\begin{tabular}{cccccc}
\hline BÖLÜM & $\mathrm{N}$ & $\mathrm{SO}$ & Kareler Ort. & $\mathrm{U}$ & $\mathrm{p}$. \\
\hline PDR & 53 & 43.94 & 2329.00 & \multirow{2}{*}{480.00} & $.029 * *$ \\
ZEÖ & 26 & 31.96 & 831.00 & & \\
\hline PDR & 53 & 48.16 & 2552.50 & \multirow{2}{*}{521.50} & $.005 * *$ \\
OÖÖ & 31 & 32.82 & 1017.50 & & \\
\hline PDR & 53 & 33.84 & 1793.50 & \multirow{2}{*}{273.50} & .451 \\
SBÖ & 12 & 29.29 & 351.50 & & \\
\hline PDR & 53 & 38.47 & 2039.00 & \multirow{2}{*}{608.00} & .559 \\
BÖTE & 25 & 41.68 & 1042.00 & & \\
\hline
\end{tabular}

Mann Whitney U Testi sonuçları incelendiğinde PDR ile Zihinsel Engelliler Öğretmenliği Bölümü (ZEÖ) $(U=480.00)$ ve Okul Öncesi Öğretmenliği Bölümü (OÖÖ) (U= 521.50) öğrencileri arasında internet bağımlılığı düzeyleri yönünden istatistiksel olarak anlamlı bir farklılık olduğu $(\mathrm{p}<.05)$ bulunmuştur. Bunun yanında PDR ile diğer bölümler arasında ise internet bağımlılı̆̆ı düzeyleri yönünden istatistiksel olarak anlamlı bir farklılık olmadığı $(\mathrm{p}>.05)$ ortaya çıkmıștır. Aralarında anlamlı farklılık bulunan bölümlerin SO dikkate alındığında PDR öğrencilerinin internet bağımlılı̆̆ı düzeyleri $(\mathrm{SO}=43.94) \mathrm{ZEÖ}(\mathrm{SO}=31.96)$ öğrencilerine göre anlamlı derecede yüksek olduğu görülmektedir. Yine PDR öğrencilerinin internet bağımlılığ düzeylerinin $(\mathrm{SO}=48.16)$ OÖÖ $(\mathrm{SO}=32.82)$ öğrencilerine göre anlamlı derecede yüksek olduğu bulunmuştur.

Tablo 8. Öğrencilerin öğrenim gördükleri bölümlerden ZEÖ ile diğer bölümler arasında ders sonrasındaki internet bă̆ımlılı̆̆ düzeylerinin de ̌̆işimi Mann Whitney U Testi tablosu

\begin{tabular}{cccccc}
\hline BÖLÜM & $\mathrm{N}$ & SO & Kareler Ort. & $\mathrm{U}$ & $\mathrm{p}$. \\
\hline ZEÖ & 26 & 30.94 & 804.50 & \multirow{2}{*}{.452 .50} & .416 \\
OÖÖ & 31 & 27.37 & 848.50 & & \\
\hline PDR & 26 & 18.58 & 483.00 & \multirow{2}{*}{132.00} & .449 \\
SBÖ & 12 & 21.50 & 258.00 & & \\
\hline PDR & 26 & 21.44 & 557.50 & \multirow{2}{*}{206.50} & .025 \\
BÖTE & 25 & 30.74 & 768.50 & & $* *$
\end{tabular}

Mann Whitney U Testi sonuçları incelendiğinde ZEÖ ile BÖTE (U= 206.50) öğrencileri arasında internet bağımlılığı düzeyleri yönünden istatistiksel olarak anlamlı bir farklılık olduğu $(\mathrm{p}<.05)$ bulunmuştur. Bunun yanında ZEÖ ile diğer bölümler arasında ise internet bağımlılığı düzeyleri yönünden istatistiksel olarak anlamlı bir farklılık olmadığı ( $>>.05)$ ortaya çıkmıştır. Anlamlı farklılık bulunan bölümler arasında BÖTE öğrencilerinin internet bağımlılığı düzeylerinin $(\mathrm{SO}=30.74) \mathrm{ZEÖ}(\mathrm{SO}=21.44)$ öğrencilerine göre anlamlı derecede yüksek olduğu görülmektedir. 
Tablo 9. Öğrencilerin öğrenim gördükleri bölümlerden OÖÖ ile diğer bölümler arasında ders sonrasındaki internet bă̆ımlılı̆̆ düzeylerinin değişimi Mann Whitney U Testi tablosu

\begin{tabular}{cccccc}
\hline BÖLÜM & $\mathrm{N}$ & SO & Kareler Ort. & $\mathrm{U}$ & p. \\
\hline OÖÖ & 31 & 20.56 & 637.50 & \multirow{2}{*}{141.60} & \multirow{2}{*}{.226} \\
SBÖ & 12 & 25.71 & 308.50 & & \\
\hline OÖÖ & 31 & 23.39 & 725.00 & \multirow{2}{*}{229.00} & \multirow{2}{*}{$.009 * *$} \\
BÖTE & 25 & 34.84 & 871.00 & &
\end{tabular}

Mann Whitney U Testi sonuçları incelendiğinde OÖÖ ile BÖTE (U= 229.00) öğrencileri arasında internet bağımlılığı düzeyleri yönünden istatistiksel olarak anlamlı bir farklılık olduğu $(\mathrm{p}<.05)$ bulunmuştur. Bunun yanında ZEÖ ile SBÖ öğrencileri arasında ise internet bağımlılığı düzeyleri yönünden istatistiksel olarak anlamlı bir farklılık olmadığı ( $\mathrm{p}>.05)$ ortaya çıkmıştır. Anlamlı farklılık bulunan bölümler arasında BÖTE öğrencilerinin internet bağımlılığı düzeylerinin $(\mathrm{SO}=34.84)$, OÖÖ $(\mathrm{SO}=23.39)$ öğrencilerine göre anlamlı derecede yüksek olduğu görülmektedir.

Tablo 10. Öğrencilerin ögrrenim gördükleri bölümlerden SBÖ ile BÖTE arasında ders sonrasındaki internet bă̆ımlılı̆̆ı düzeylerinin değişimi Mann Whitney U Testi tablosu

\begin{tabular}{cccccc}
\hline BÖLÜM & N & SO & Kareler Ort. & U & p. \\
\hline SBÖ & 12 & 16.17 & 194.00 & 116.00 & .269 \\
BÖTE & 25 & 20.36 & 509.00 & & \\
\hline
\end{tabular}

Mann Whitney U Testi sonuçları incelendiğinde SBÖ ile BÖTE (U= 116.00) öğrencileri arasında internet bağımlılığı düzeyleri yönünden istatistiksel olarak anlamlı bir farklılık olmadığı (p>.05) bulunmuştur. Tüm bu bulgular PDR ile BÖTE öğrencilerinin internet bağımlılığı düzeylerinin oldukça yüksek olduğunu göstermektedir. Bunun yanında SÖ, ZEÖ ve OÖÖ öğrencilerinin ise internet bağımlılığı düzeylerinin PDR ile BÖTE'ye göre oldukça düşük olduğu ortaya çıkmıştır. Öğrencilerin öğrenim gördükleri bölümleri yönünden öğrencilerin ders öncesinden sonrasına internet bağımlılığı düzeylerinin değişip değişmediğine ilişkin Wilcoxon İşaretli Sıralar Testi yapılmıştır. Wilcoxon İşaretli Sıralar Testinden elde edilen bulgular aşağıdaki tabloda sunulmuştur. 
Tablo 11. Öğrencilerin öğrenim gördükleri bölümlere göre ders öncesi ve sonrasındaki internet bağımlılı̆̆ düzeylerinin değişip değişmediğine yönelik Wilcoxon Işsaretli Stralar Testi sonuçları

\begin{tabular}{llccccc}
\hline \multicolumn{1}{c}{ Ders Öncesi - Ders Sonrast } & $n$ & SO & Sira Top. & $z$ & $p$ \\
\hline S. Ö. & Negatif Sıra & 48 & 42.50 & 2040.00 & & \\
& Pozitif Sıra & 35 & 41.31 & 1446.00 & -1.35 & .177 \\
& Eşit & 5 & & & & \\
\hline PDR & Negatif Sıra * & 21 & 21.45 & 450.50 & & \\
& Pozitif Sıra & 29 & 28.43 & 824.50 & -.837 & .046 \\
& Eşit & 3 & & & & \\
\hline ZEÖ & Negatif Sıra & 17 & 13.41 & 228.00 & & \\
& Pozitif Sıra * & 5 & 5.00 & 25.00 & -3.301 & .001 \\
& Eşit & 4 & & & & \\
\hline \multirow{3}{*}{ OÖÖ } & Negatif Sıra & 19 & 14.37 & 273.00 & & \\
& Pozitif Sira & 10 & 16.20 & 162.00 & -1.202 & .229 \\
& Eşit & 2 & & & & \\
\hline SBÖ & Negatif Sıra & 3 & 9.33 & 28.00 & & \\
& Pozitif Sira & 8 & 4.75 & 38.00 & -.449 & .653 \\
& Eşit & 1 & & & & \\
\hline BÖTE & Negatif Sıra & 8 & 7.44 & 59.50 & & \\
& Pozitif Sıra & 10 & 11.15 & 111.50 & -1.134 & .257 \\
& Eşit & 7 & & & & \\
\hline
\end{tabular}

Wilcoxon İşaretli Siralar Testi sonucunda; PDR ve ZEÖ'deki öğrencilerin internet bağımlılığı düzeylerinin ders öncesinden sonrasina istatistiksel olarak $\left(\mathrm{z}_{(\mathrm{PDR})}=-.837 \mathrm{ve}\right.$ $\left.\mathrm{Z}_{(\mathrm{ZEO})}=-3.301, \mathrm{p}>.05\right)$ anlamlı derecede değişim gösterdiği bulunmuş̧ur. Diğer bölümlerde ise anlamlı derecede değişim yoktur. Bu bölümlerden PDR'de internet bağımlılığı düzeyleri anlamlı düzeyde artarken, ZEÖ'de ise internet bağımlılığı düzeyinin anlamlı derecede azaldığı görülmektedir. Araştırmada son olarak öğrencilerin SED'lerine ilişkin Kruskal Wallis H Testi yapılmıştır. Bu test sonucunda elde edilen bulgular aşağıdaki tabloda yer almaktadır.

Tablo 12. Öğrencilerin SED’lerine göre ders öncesi ve sonrasindaki internet bağımlılı̆̆ı düzeylerinin Kruskal Wallis H Testi sonuçları

\begin{tabular}{llccccc}
\hline & SED & N & SO & $\chi^{2}$ & df & p \\
\hline \multirow{2}{*}{ Ders } & 483YTL ve Alt1 & 43 & 131.99 & & & \\
Öncesi & 484-800 YTL & 75 & 113.88 & 2.259 & 2 & .323 \\
& 801 YTL ve Üzeri & 117 & 115.50 & & & \\
\hline \multirow{2}{*}{ Ders } & 483YTL ve Alt1 & 43 & 120.16 & & & \\
Sonras1 & 484-800 YTL & 75 & 127.17 & 2.545 & 2 & .280 \\
& 801 YTL ve Üzeri & 117 & 111.32 & & & \\
\hline
\end{tabular}


Araştırmaya katılan öğrencilerin internet bağımlılık düzeyleri SED'lerine göre karşılaştırıldığında ders öncesinde $\left(\chi^{2}=2.259, \mathrm{p}>.05\right)$ ve sonrasinda $\left(\chi^{2}=2.545\right.$, $\mathrm{p}>.05)$ istatistiksel olarak anlamlı bir farklılık olmadığı görülmektedir. Öğrencilerin SED'lerine göre ders öncesinden sonrasina internet bağımlılığı düzeylerinin değişip değişmediğine Wilcoxon İşaretli Sıralar Testi ile bakılmıştır. Test sonuçlarından her üç alt grupta da istatistiksel olarak anlamlı farklılık olmadığı bulunmuş̧ur. Bu bulgu, öğrencilerin SED’lerinin internet bağımlılı̆̆ düzeylerine etkisinin anlamlı olmadığını ortaya koymaktadır.

\section{SONUÇ VE ÖNERILER}

Araştırmada cinsiyet yönünden erkek öğrencilerin kız öğrencilere göre internet bağımlılığı düzeylerinin yüksek olduğu bulunmuş̧tur. Cinsiyet yönünden erkek ve kız öğrencilerin ders öncesinden sonrasına internet bağımlılığı düzeyleri değişmemektedir. Bu bulgu Morahan-Martin ve Schumacker (2000); Soule ve diğerleri (2003) ve Chou ve diğerlerinin (2005) bulgularıyla tutarlı; Young (1998), Brenner (1997) Soule ve diğerleri (2003) Lee ve diğerleri (2007) ile Ferraro ve diğerlerinin (2007) yaptığ araştırmalarındaki bulgularla farklılık göstermektedir. Bu farklılığın, araştırmalardaki internet bağımlılık düzeyinin ölçüm biçiminden ve/veya ülkelerin farklı olması nedeniyle kültürel farklılıklar gibi değişkenlerden kaynaklanmış olacağı şeklinde yorumlanabilir. Özellikle Türkiye'de kızlar internete evden ulaşabilirken, erkeklerin internete hem evden, hem de internet kafeden yani istediği yerden erişebilmesi dersten önce ve sonra erkeklere yönelik bağımlılık düzeyinin fazlalığının nedeni olarak görülebilir.

Araştırmada ikinci olarak haftada sekiz saatten fazla internete bağlı kalanların, haftada sekiz saatten az internete bağlı kalan öğrencilerden internet bağımlılık düzeyi olarak daha yükssek olduğu ortaya çıkmıştır. Bu bulgu: Scherer, Nalwa ve Anand (2003) Yoo ve diğerleri (2004) Chou ve diğerleri (2005) ile Morahan-Martin ve Schumacker'in (2000) araştırmalarıyla tutarlılık göstermektedir. Bunun yanında haftalık internet kullanım süreleri yönünden haftada sekiz saatten fazla bağlı kalanlar ile sekiz saatten az bağlı kalan öğrencilerin ders öncesinden sonrasına internet bağımlılığı düzeylerinin değişmediği bulunmuştur.

Araştırmada üçüncü olarak internet bağımlılık düzeyinin öğrenim görülen bölümlere göre değişip değişmediğine bakılmıştır. Bu açıdan ders öncesinde internet bağımlılık düzeyleri istatistiksel olarak anlamlı bir farkllılı göstermemesine rağmen, ders sonrasında istatistiksel olarak anlamlı bir farklılık göstermektedir. Bölümlerin hangisinde farklılık olduğuna bakıldı̆̆ında PDR ile BÖTE öğrencilerinin internet bağımlılığı düzeylerinin oldukça yüksek olduğu, bunun yanında SÖ, ZEÖ ve OÖÖ’ndeki ögrencilerin ise internet bağımlılığı düzeylerinin PDR ile BÖTE'ye göre oldukça düşük olduğu bulunmuştur. Bu bölümlerden PDR'de internet bağımlılığ 1 düzeylerinin ders öncesinden sonrasına anlamlı düzeyde artarken, ZEÖ'nde ise internet bağımlılı̆̆ düzeyinin anlamlı derecede azaldığı bulunmuştur. Bu bulgu ile ilgili alan yazında bir araştırmaya rastlanamamıştır. Ancak Young'ın (1998), işi veya öğrenimi tamamen bilgisayar veya internet üzerinden olan kişiler ile, işi veya öğrenimi doğrudan 
bilgisayar veya internet ile ilişkili olanların daha fazla internette kaldıklarını ve bu kişilerin bağımlı olma eğilimlerinin arttığı ifadesi BÖTE'deki öğrencilerin internet bağımlılık düzeylerinin artmasını açıklayıcı nitelikte görülebilir. Özellikle ders öncesinde bu bölümle diğer bölümler arasinda anlamlı farklılık bulunmaması bölümdeki araştırmaya katılan öğrencilerden teknik lise mezunlarının sayısının düşük, düz lise mezunlarının sayısının fazla olmasından kaynaklı olduğu söylenebilir. Bunun yanında bu bölümde diğer bölümlere göre Bilgisayar I dersinin kredisinin fazla olması ve bölümün, bilgisayar ve interneti temel alan bir bölüm olması, öğrencilerin internet bağımlılık düzeyini artıran neden olarak yorumlanabilir. Bununla birlikte, PDR öğrencilerinin bağımlılıklarının ders öncesinden sonrasına anlamlı derecede artmasının nedeni olarak; bu bölümdeki öğrencilerden büyük bir bölümünün bir önceki sene böyle bir eğitimi almış olmalarından, bu eğitime daha çok adapte olmaları ve bu öğrencilerin ikinci sınıfta bu dersi almalarından kaynaklandığı düşünülebilir.

Araştırmada son olarak öğrencilerin SED’lerinin internet bağımlılığı düzeylerine etkisinin anlamlı olmadığı bulunmuştur. Bu bulgu da Yoo ve diğerlerinin (2004) araştırmasındaki bulgu ile tutarlılık göstermektedir. Bu çalışmada PDR öğrencilerinin BÖTE öğrencileri kadar diğer bölümlerden yüksek internet bağımlığı̆ı düzeyleri bulunmuştur. Bundan sonraki araştırmalarda bu konu ve sebebi hakkında ayrıntılı araştırmalar yapılabilir. Araştırmada içerik olarak uygulamalı bir ders içeriği olan bilgisayar ve internet kullanımı ile ilgili bir ders olan Bilgisayara Giriş dersi verilmiş̧ir. Bundan sonraki araştırmalarda bilgisayar harici sayısal ve sözel içerikli dersler internet üzerinden iletilerek internet bağımlılığına etkisi incelenebilir.

Araştırmada öğrencilerin bilgisayar dersine yönelik korkuları ve tutumlarına bakılmamıştır. Bu değişkenler hem bağımlı değişken olarak hem de kontrol değişkeni olarak diğer araştırmalarda konu edilebilirler. Bu araştırmada sadece internet bağımlılık düzeyleri ve bunu etkileyen değişkenler konu edilmiştir. Bundan sonraki araştırmalarda internet bağımlılığı yüksek öğrencilerin interneti kullanım biçimleri, bağlandığı siteler ve buralara bağlanma nedenleri derinlemesine incelenerek konu edilebilir.

İleriki çalışmalarda Young tarafindan geliştirilen İnternet Bağımlılığı Ölç̧eği aracılı̆̆ ile ölçülen internet bağımlılık düzeyleri ile internet üzerinden öğrenim gören öğrencilerin başarıları, internet üzerinden eğitime yönelik doyumları ile ilgili çalışmalar da yapılabilir. Aynı dersi uzaktan ve yüz yüze öğrenen öğrencilerin internet bağımlılık düzeyleri bakımından fark olup olmadığına bakılabilir. Bundan sonraki araştırmalarda yapılan araştırma daha da genelleştirilerek, Türkiye'deki tüm öğrencilerin internet bağımlılık düzeyleri tespit edilebilir. İnternetin hangi düzeyde, ne amaçla kullanıldığının belirlenmesi için çalışmalar yapılabilir. 


\section{KAYNAKLAR}

Beard, K.W. (2005). Internet addiction: A review of current assessment techniques and potential assessment questions. Cyberpsychology \& Behavior, 8(1), 7-14.

Brenner, V. (1997). Psychology of computer use: XLVII. Parameters of Internet use, abuse and addiction: The first 90 days of the Internet usage survey. Psychol. Rep. 80: 879-882.

Cengizhan, C. (2003). Bilgisayar ve İnternet Bağımlılı̆ı̆. IX. Türkiye'de İnternet Konferans1. Askeri Müze ve Kültür Sitesi Harbiye İstanbul, 11-13 Aralık 2003. http://mimoza.marmara.edu.tr/ cahit/Yayin.html adresinden 10.04 .2005 tarihinde erişilmiştir.

Ceyhan, E., Ceyhan, A.A. ve Gürcan, A. (2007). Problemli İnternet Kullanımı Ölçeği'nin Geçerlilik ve Güvenirlilik Çalışmaları. Kuram ve Uygulamada Ĕgitim Bilimleri Dergisi, 7 (1), 387-416.

Chak, K. \& Leung, L. (2004). Shyness and locus of control as predictors of internet addiction and internet use. Cyberpsychology \& Behavior, 7(5), 559-570

Chou, C. \& Hsiao, M.C. (2000). Internet addiction, usage, gratification, and pleasure experience: The Taiwan college students' case. Computers and Education, 35, 65-80,

Chou, C., Condron, L. \& Belland, J.C. (2005). A Review of the Research on Internet Addiction. Educational Psychology Review, 17(4), 363-388.

Ferraro, G., Caci, B., D'amico, A. \& Blasi, M.D. (2007). Internet Addiction Disorder: An Italian Study. Cyberpsychology \& Behavior. 10(2), 170-175.

Griffiths, M.D. (2000). Does Internet and computer "addiction" exist? Some case study evidence. Cyberpsychology \& Behavior, 3(2), 211-218.

Griffiths, M.D. (2005). A "components" model of addiction within a biopsychosociaI framework, journal of Substance Abuse, 10(4), p. 191-197,

İnternet hastasıyım doktor bey! (16 Ağustos 2006). Milliyet, Bilim ve Teknoloji. http://teknoloji.milliyet.com.tr/detay.asp?id=1776 adresinden $\quad 10.07 .2007$ tarihinde erișilmiștir.

İnternet resmen h@st@l1k! (10 Ağustos 2006). Milliyet, Bilim ve Teknoloji. http://teknoloji.milliyet.com.tr/detay.asp?id=1756 adresinden $\quad 10.07 .2007$ tarihinde erişilmişsir.

Kandell, J. (1998). Internet addiction on campus - the vulnerability of college students. Cyberpsychology \& Behavior, 1, 46-59.

Karasar, N. (2004). Bilimsel Araştırma Yöntemi (15. Baskı). Ankara: Nobel Yayın Dağıtım.

Köroğlu, G., Öztürk, Ö., Tellioğlu, N., Genç, Y., Mırsal, H. ve Beyazyürek, M. (2006). Problemli İnternet Kullanımıyla Başvuran İki Uçlu Bir Hasta Nedeniyle Psikiyatrik Ek Tanı Tartışması: Olgu Sunumu. Bağımlllık Dergisi, 7(3), 150-154. 
Lee, M-S., Ko, Y-H., Song, H-S., Kwon, K.-H., Lee, H-S., Nam, M. \& Jung, I-K., (2007). Characteristics of internet use in relation to game genre in Korean adolescents. Cyberpsychology \& Behavior. 10(2), 278-285.

Morahan-Martin, J. M., \& Schumacker, P. (2000). Incidence and correlates of pathological internet use. Computer Human Behaviour 16: 13-29.

Nalwa, K. \& Anand, A.P. (2003). Internet addiction in students: A cause of concern. Cyberpsychology \& Behavior, 6(6). 653-656

Ngai, S. S-Y., (2007). Exploring the validity of the internet addiction test for students in grades 5-9 in Hong Kong. International Journal of Adolescence and Youth, Volume 13, 221-237.

Öztürk, Ö., Odabaşıoğlu, G., Eraslan, D., Genç, Y. ve Kalyoncu, A. (2007). İnternet Bağımlılığı: Kliniği ve Tedavisi: Bağımlıllk Dergisi, 8(1), 36-41.

Soule, L. C., Shall, W. \& Kleen, B.A. (2003). Exploring internet addiction: Demographic characteristics and stereotypes of heavy internet users. Journal of Computer Information Systems. Fall, 64-73.

Tsai, C.C. \& Lin, S.S.J. (2003). Internet addiction of adolescents in Taiwan: An interview study. Cyberpsychology \& Behavior, 6(6), 649-652.

Türkiye, net’te yüzde 700 büyüdü (9 Temmuz 2007). Milliyet, Bilim ve Teknoloji. http://teknoloji.milliyet.com.tr/detay.asp?id=2939 adresinden $\quad 10.07 .2007$ tarihinde erişilmiştir.

Yoo, H.J., Cho, S.C., Ha, J., Yune, S.K., Kim, S.J., Hwang, J., Chung, A., Sung, Y.H. ve Lyoo, I.K. (2004). Attention deficit hyperactivity symptoms and internet addiction. Psychiatry and Clinical Neurosciences (2004), 58, 487-494.

Young, K. (1997). What makes the internet addictive: Potential explanations for pathological internet use. Paper presented at the 105th annual conference of the American Psychological Association. August 15, 1997, Chicago, IL. http://www.netaddiction.com/articles/habitforming.htm adresinden 10.04.2005 tarihinde erişilmiştir.

Young, K. (1998). Internet addiction: The emergence of a new clinical disorder. Cyberpsychology \& Behavior, 1 (3), 237-244.

Young, K. (1998). "Caught in the Net" http://www.netaddiction.com/ adresinden 01.10.2007 tarihinde erişilmiştir.

Young, K. (1999). Internet addiction: Symptoms, evaluation, and treatment. In L. VandeCreek \& T. Jackson (Eds.). Innovations in Clinical Practice: A Source Book (Vol. 17; pp. 19-31). Sarasota, FL: Professional Resource Press.

Young, K. (2005). "Surfing not studying: Dealing with internet addiction on campus" http://www.netaddiction.com/articles/surfing_not_studying.htm adresinden 10.04.2005 tarihinde erişilmiştir. 